\title{
Menurunkan Keluhan Gangguan Muskuloskeletal Pada Penenun Tradisional Sarung Samarinda Melalui Pelatihan Peregangan Otot di Tempat Kerja
}

\author{
Iwan Muhamad Ramdan ${ }^{1}$ \\ Fakultas Kesehatan Masyarakat, Universitas Mulawarman, \\ iwanmuhamadramdan@gmail.com \\ Azizah Azahra2 \\ Fakultas Kesehatan Masyarakat, Universitas Mulawarman, aazzahrah15@yahoo.com
}

\begin{abstract}
Abstrak
Gangguan muskuloskeletal merupakan masalah kesehatan kerja di seluruh dunia, baik pada pekerja sektor formal maupun informal dan telah menimbulkan kerugian yang cukup besar baik bagi dunia usaha maupun bagi pekerja. Salah satu upaya pencegahan gangguan muskuloskeletal adalah dengan pemberian pelatihan peregangan otot di tempat kerja (muscle streching exercise). Kegiatan pengabdian masyarakat bagian Kesehatan dan Keselamatan Kerja Fakultas Kesehatan Masyarakat Universitas Mulawarman dilaksanakan di Kelurahan Tenun Kota Samarinda yang merupakan ikon pariwisata Kota Samarinda Kalimantan Timur. Sasaran pengabdian masyarakat adalah penenun tradisional sarung Samarinda yang berjumlah 75 orang. Kegiatan dimulai dengan pengukuran gangguan muskuloskeletal dengan instrumen Nordic Body Map, kemudian penjelasan tujuan dan manfaat kegiatan, pemberian peregangan otot di tempat kerja disela-sela kegiatan menenun 2 kali setiap minggu selama 1 bulan, dan diakhiri dengan pengukuran kembali gangguan muskuloskeletal. Sebelum pelaksaan intervensi, gangguan muskuloskeletal pada penenun didapatkan kategori rendah $(49,4 \%)$, kategori menengah (32,5\%), kategori tinggi (15,5\%). Evaluasi 2 minggu pertama didapatkan gangguan muskuoskeletal kategori rendah $(81,8 \%)$ dan kategori menengah $(15,6 \%)$, dan evaluasi 2 minggu kedua didapatkan hasil gangguan musculoskeletal kategori sangat rendah $(32,2 \%)$, rendah $(44,2)$ dan menengah $(20,8 \%)$. Disimpulkan, peregangan otot di tempat kerja dapat menurunkan keluhan gangguan muskuloskeletal walaupun belum semuanya teratasi. Kegiatan ini sangat bermanfaat bagi penenun tradisional sarung Samarinda dalam rangka pencegahan kejadian gangguan muskuloskeletal yang lebih parah
\end{abstract}

Kata Kunci: Latihan Peregangan Otot di Tempat Kerja, Gangguan Muskuloskeletal, Penenun Tradisional Sarung Samarinda

\section{Abstract}

Musculoskeletal disorders are occupational health problems throughout the world, both for formal and informal sector workers and have caused considerable losses both for the business 
world and for workers. One of the efforts to prevent musculoskeletal disorders is by giving muscle stretching exercise. Community service activities in the Occupational Health and Safety Department of the Public Health Faculty of Mulawarman University were carried out in the Tenun Village of Samarinda City, which is an tourism icon of Samarinda City, East Kalimantan. The target of community service is the traditional weavers of Sarong Samarinda, amounting to 75 people. The activity begins with the measurement of musculoskeletal disorders with the Nordic Body Map instrument, then explains the purpose and benefits of the activity, giving muscle stretching exercises between weaving activities 2 times every week for 1 month, and ends with the re-measurement of musculoskeletal disorders. Before the intervention, musculoskeletal disorders in weavers were found in the low category (49.4\%), the middle category (32.5\%), and the high category (15.5\%). The first 2 weeks evaluation, musculoskeletal disorders in weavers were found in the low category (81.8\%) and middle category (15.6\%). The second 2 weeks evaluation, musculoskeletal disorders in weavers were found in the very low category (32.2\%), low category (44.2\%) and intermediate $(20.8 \%)$. In conclusion, muscle stretching exercise can reduce complaints of musculoskeletal disorders, although not all of them are resolved. This activity is very beneficial for Samarinda's traditional weavers in order to prevent the more severe occurrence of musculoskeletal disorders

Keywords: Workplace stretching exercise, Musculoskeletal disorders, Sarong Samarinda Traditional Weavers.

\section{Pendahuluan}

Gangguan muskuloskeletal akibat kerja adalah masalah kesehatan pada alat gerak berupa cedera jaringan lunak yang disebabkan oleh pembebanan otot dan tulang yang tiba-tiba atau berkelanjutan, gerakan berulang dalam waktu yang lama, paparan getaran, pembebanan yang melebihi kapasitas, posisi duduk statis yang cukup lama dan posisi kerja yang canggung, kondisi ini dapat mempengaruhi otot, ligamen, saraf, tendon dan persendian (Anderson et al., 1997; Luttmann et al., 2003). Prevalensi gangguan muskuloskeletal akibat kerja di dunia cukup tinggi. Sebagai gambaran menurut Bereau of Labor Statistic, US Department of Labor (BLS), pada tahun 2015 jumlah kejadaian gangguan muskuloskeletal akibat kerja di Amerika mencapai 356.910 kasus(Bureau of Labor and Statistics, 2016). Di Inggris pada tahun 2017 Labour Force Survei (LFS) Great Britain menyimpulkan gangguan muskuloskeletal menempati urutan kedua penyakit akibat kerja dengan rata-rata prevalensi 469.000 kasus atau 34,54\% selama 3 tahun terakhir (Scheneider \& Irastorza, 2010). Di Indonesia sendiri, prevalensi gangguan muskuloskeletal yang berhubungan dengan faktor pekerjaan cukup tinggi. Studi Departemen Kesehatan Republik Indonesia menyimpulkan sekitar $40,5 \%$ penyakit yang diderita pekerja berhubungan dengan pekerjaan. Gangguan kesehatan yang dialami pekerja berdasarkan penelitian yang dilakukan pada 9.482 pekerja di 12 kabupaten/kota di Indonesia menunjukkan angka tertinggi yaitu gangguan muskuloskeletal (16\%), disusul gangguan kardiovaskular $(8 \%)$, gangguan saraf $(5 \%)$, gangguan pernapasan $(3 \%)$ serta gangguan THT (1.5\%) (Sekaaram \& Ani, 2017). 
Berdasarkan evaluasi kinerja pembangunan kesehatan tahun 2017, kejadian penyakit punggung bagian bawah sebagai salah satu jenis gangguan muskuloskeletal menduduki peringkat 1 atau jumlah tahun hidup dengan kecacatan/ cedera, sementara untuk jenis gangguan muskuloskeletal lainnya berada pada peringkat 6 (Kementrian Kesehatan Republik Indonesia, 2019).

Gangguan muskuloskeletal telah menimbulkan kerugian yang cukup besar baik di negara maju maupun negara berkembang (Wang et al, 2017). Penyakit akibat kerja ini tidak hanya berdampak terhadap individu tenaga kerja, namun berpengaruh juga terhadap kelangsungan dunia usaha termasuk diantaranya penurunan produktivitas kerja, penurunan kesejahteraan hidup pekerja, peningkatan biaya kesehatan, penurunan kepuasan kerja, degradasi kualitas kesehatan fisik dan mental, dan penurunan kemampuan untuk melakukan aktivitas fisik lainnya (Dinar, Susilowati, Azwar, Indriyani, \& Wirawan, 2018; Bhattacharya, 2014; Loghmani, Golshiri, Zamani, Kheirmand, \& Jafari, 2013; Valsangkar \& Sai, 2012).

Tenun Samarinda adalah salah satu ikon pariwisata di Kota Samarinda Provinsi Kalimantan Timur, berlokasi di Kelurahan Tenun Kecamatan Samarinda Seberang Kota Samarinda. Industri non formal ini telah berlangsung sejak tahun 1607 (Purwadi, 2015), sampai saat ini masih dipertahankan dan terus dibina oleh pemerintah setempat, karena mempunyai nilai artistik yang cukup tinggi, mengharumkan nama Kota Samarinda dan dapat menopang perekonomian setempat. Aktivitas menenun dilakukan secara manual dengan bantuan alat tenun bukan mesin (ATBM). Untuk menghasilkan 1 lembar kain sarung berukuran $200 \mathrm{X}$ $80 \mathrm{~cm}^{2}$ dibutuhkan waktu sekitar 4 sampai 5 hari. Hasil penelitian pendahuluan oleh Muhamad Ramdan, Candra, \& Rahma Fitri (2018) menyimpulkan prevalensi kejadian gangguan muskuloskeletal yang cukup tinggi yaitu $85 \%$ dengan kategori gangguan muskuloskeletal rendah (15\%), moderat (7,5\%) dan tinggi $(77,5 \%)$. Keluhan gangguan muskuloskeletal yang paring sering dialami adalah leher bawah, bahu, lengan atas, pantat, paha, betis dan pergelangan kaki.

Terdapat beberapa upaya yang dapat dilakukan untuk mencegah dan menanggulangi gangguan muskuloskeletal akibat kerja, diantaranya adalah pendekatan ergonomik, pendekatan perilaku dan pendekatan organisasi (Leyshon et al., 2010; Hogan, Greiner, \& O'Sullivan, 2014; Stock et al., 2018). Pelatihan peregangan otot di tempat kerja adalah salah satu intervensi yang cukup banyak dilakukan untuk mencegah gangguan muskuloskeletal karena dianggap murah, mudah dan terbukti dapat mencegah gangguan muskuloskeletal yang lebih buruk (Rovitri, Lubis, \& Sinaga, 2015; Wahyono \& Saloko, 2014; Harwanti, Ulfah, \& Aji, 2017).

Pengabdian kepada masyarakat oleh Fakultas Kesehatan Masyarakat Universitas Mulawarman ini bertujuan untuk mengatasi permasalah gangguan muskuloskeletal yang dialami oleh penenun tradisional Sarung Samarinda melalui peregangan otot di tempat kerja. Setelah program ini selesai, diharapakan masyarakat setempat (penenun tradisional Sarung Samarinda) dapat menolong dirinya sendiri dalam upaya pencegahan gangguan muskuloskeletal akibat aktivitas menenunnya. 


\section{Metode}

Kegiatan pengabdian kepada masyarakat berupa peregangan otot di tempat kerja pada penenun tradisional Sarung Samarinda telah dilaksanakan pada bulan Februari-Maret 2019, dan dilakukan dalam 3 tahapan yaitu: 1)persiapan; 2) Pelaksanaan/implementasi dan 3) Evaluasi.

Tahapan persiapan terdiri dari studi awal untuk memastikan apakah gangguan musculoskeletal yang dialami oleh penenun tradisional Sarung Samarinda seperti hasil penelitian terdahulu masih terjadi. Pengukuran gangguan muskuloskeletal menggunakan kuesioner Nordic Body Map yang sudah tervalidasi (Ramdan, Duma, \& Setyowati, 2019). Setelah data gangguan muskuloskeletal diperoleh, kemudian diolah dan dianalisis sebagai data awal, yang akan dibandingkan dengan data gangguan muskuloskeletal setelah pemberian intervensi. Selanjutnya persiapan tempat/lokasi berupa pengurusan perijinan dan pendekatan dan penjelasan kepada ketua kelompok usaha tenun dan anggotanya tentang rencana kegiatan yang akan dilaksanakan, serta persiapan bahan dan alat pengabdian masyarakat.

Pelaksanaan kegiatan pengabdian kepada masyarakat dikemas dalam bentuk pemberian pelatihan peregangan otot di tempat kerja dari pintu ke pintu, artinya Dosen (beserta mahasiswa) mendatangi penenun ke rumah-rumah untuk memberikan penjelasan sekaligus praktek. Hal ini dilakukan karena usaha tenun adalah usaha perorangan berbentuk industri rumahan yang mana seluruh penenun menjadikan rumahnya sebagai tempat usaha. Intervensi peregangan otot di tempat kerja diberikan disela-sela penenun bekerja 2 kali seminggu (setiap hari senin dan kamis) selama 1 bulan.

Evalusi keberhasilan intervensi dilaksanakan pada minggu ke dua dan minggu ke empat pelatihan. Evaluasi keberhasilan program didasarkan atas perubahan keluhan gangguan musculoskeletal setelah dua minggu dan empat minggu intervensi. Gangguan musculoskeletal yang dilaporkan oleh penenun adalah keluhan nyeri pada leher atas, leher bawah, bahu kiri dan kanan, lengan atas kiri dan kanan, punggung, pinggang, pantat, siku kiri dan kanan, lengan bawah kiri dan kanan, pergelangan tangan kiri dan kanan, tangan kiri dan kanan, paha kiri dan kanan, lutut kiri dan kanan, betis kiri dan kanan, pergelangan kaki kiri dan kanan, serta kaki kiri dan kanan. Penilaian keluhan nyeri terdiri dari 4 skala yaitu: sangat nyeri (skor 3), nyeri (skor 2), kadang-kadang nyeri (skor 1) dan tidak nyeri (skor 0).

\section{Hasil dan Pembahasan}

Gerakan peregangang yang diaplikasikan pada penenun tradisional ini adalah gerakan yang berfokus pada leher, bahu, lengan, tangan, punggung dan kaki yang berfungsi melenturkan otot-otot pada bagian yang difokuskan. Penguluran atau peregangan pada otot-otot dilakukan dengan 29 gerakan secara bertahap, setiap gerakan dilakukan penahanan selama delapan detik untuk merasakan adanya tarikan pada otot-otot yang difokuskan.

Rincian latihan peregangan otot di tempat kerja dalam kegiatan ini adalah: 1) gerakan berfokus pada leher, wajah, bahu, lengan, tangan, punggung, dan kaki; 2) setiap gerakan dilakukan penahanan selama 5-10 detik untuk merasakan adanya tarikan pada otot- otot yang difokuskan; 3) dilakukan pengulangan 3-5 kali untuk 
setiap gerakan; 4) selanjutnya latihan peregangan diaplikasikan setiap hari senin dan kamis sesaat setelah penenun bekerja selama 1 bulan.

Tabel 1. Karakteristik subjek pengabdian

\begin{tabular}{|c|c|c|c|}
\hline No & Karakter & Frekuensi & $\%$ \\
\hline \multirow[t]{3}{*}{1} & Umur & & \\
\hline & - $\quad<35$ tahun & 18 & 23,4 \\
\hline & - $>35$ tahun & 55 & 71,4 \\
\hline \multirow[t]{5}{*}{2} & Pendidikan & & \\
\hline & - $\mathrm{SD}$ & 50 & 64,9 \\
\hline & - SLTP & 9 & 11,7 \\
\hline & - SLTA & 3 & 3,9 \\
\hline & - Perguruan Tinggi & - & \\
\hline \multirow[t]{4}{*}{3} & Waktu kerja & & \\
\hline & - $1-6$ jam per hari & 62 & 82,6 \\
\hline & - $\quad>6-8$ jam per hari & 10 & 13,3 \\
\hline & - $>8-10$ jam per hari & 3 & 4 \\
\hline \multirow[t]{5}{*}{4} & Masa kerja & & \\
\hline & - $<5$ tahun & 6 & 8 \\
\hline & - $\quad>10-15$ tahun & 26 & 34,6 \\
\hline & - $>15-20$ tahun & 6 & 8 \\
\hline & - $>20$ tahun & 37 & 49,3 \\
\hline
\end{tabular}

Sumber: data primer diolah

Dari total 75 orang subjek pengabdian, sebagian besar penenun tradisional Sarung Samarinda berumur lebih dari 35 tahun $(71,4 \%)$, berpendidikan lulusan sekolah dasar $(64,9 \%)$, waktu kerja per hari sebagian besar 1-6 jam perhari (62\%) dan masa kerja sebagian besar lebih dari 20 tahun (48,1\%) (Tabel 1).

Tabel 1. Karakteristik subjek pengabdian

Gangguan musculoskeletal pada penenun tradisional Sarung Samarinda sebelum dan sesudah pemberian latihan peregangan otot di tempat kerja

\begin{tabular}{lcccccc}
\hline \multirow{2}{*}{ Gangguan Muskuloskeletal } & \multicolumn{2}{c}{ Data awal } & \multicolumn{3}{c}{ Evaluasi intervensi } \\
\cline { 2 - 7 } & \multicolumn{2}{c}{ Sebelum intervensi } & 2 minggu pertama & \multicolumn{2}{c}{2 minggu kedua } \\
\cline { 2 - 7 } & Frekuensi & $\%$ & Frekuensi & $\%$ & Frekuensi & $\%$ \\
\hline Kategori sangat rendah & - & - & - & - & 25 & 32,5 \\
Kategori rendah & 38 & 49,4 & 63 & 81,1 & 34 & 44,2 \\
Kategori menengah & 25 & 32,5 & 12 & 15,6 & 16 & 20,8 \\
Kategori tinggi & 12 & 15,6 & - & - & - & - \\
Kategori sangat tinggi & - & - & - & - & - & - \\
\hline
\end{tabular}

Hasil pengukuran sebelum intervensi didapatkan gangguan muskuloskeletal kategori rendah (49,4\%), kategori menengah (32,5\%), kategori tinggi (15,5\%). Hasil evaluasi intervensi pada 2 minggu pertama didapatkan data: gangguan muskuloskeletal kategori rendah $(81,8 \%)$ dan kategori menengah $(15,6 \%)$. Hasil evaluasi intervensi pada 2 minggu kedua (terakhir) didapatkan data: gangguan 
muskuloskeletal kategori sangat rendah $(32,2 \%)$, rendah $(44,2)$ dan menengah $(20,8 \%)$ (Tabel 2).

Dari table 2 dapat disimpulkan bahwa latihan peregangan otot di tempat kerja dapat menurunkan keluhan gangguan musculoskeletal pada penenun tradisional Sarung Samarinda. Walaupun intervensi ini belum mencapai hasil maksimal (dapat menurunkan keluhan gangguan muskuloskeletal hingga ke skor terendah), namun intervensi ini dinilai cukup bermanfaat dalam rangka pencegahan gangguan musculoskeletal yang lebih parah.

Seperti pendapat Anderson (2010), gerakan peregangan otot sangat sederhana dan mudah dilakukan. Latihan peregangan ini dapat dilakukan hampir di segala tempat dan kapan saja, tidak memerlukan peralatan khusus, tidak memerlukan pakaian khusus dan tidak memerlukan ketrampilan khusus. Mekanisme penurunan derajat nyeri yang terjadi pada penenun berhubungan dengan menurunnya spasme otot dan peningkatan sirkulasi darah pada otot. Hal ini sejalan dengan teori gerbang kontrol yaitu melalui efek latihan peregangan otot di tempat kerja.

Berdasarkan hasil penelitian sebelumnya, keluhan gangguan musculoskeletal yang dirasakan oleh penenun berhubungan dengan posisi duduk stasis yang cukup lama, ukuran/ketinggian meja dan kursi tenun yang kurang ergonomis, serta material kursi tenun yang seluruhnya terbuat dari kayu sehingga terasa keras/kurang nyaman. Waktu kerja yang cukup lama dengan posisi duduk statis dapat menyebabkan ketegangan dan penekanan pada otot-otot sekitar pantat, paha dan pergelangan kaki. Jika tidak diberikan intervensi, kondisi ini akan menjadikan keluhan nyeri yang dirasakan akan bertambah berat.

\section{Simpulan dan Rekomendasi}

Kegiatan pengabdian kepada masyarakat berupa latihan peregangan otot di tempat kerja pada penenun tradisional Sarung Samarinda berhasil menurunkan gangguan muskuloskeletal dengan indikator utama terjadinya penurunan keluhan nyeri pada berbagai bagian tubuh. Evaluasi 2 minggu pertama dan 2 minggu kedua setelah intervensi berhasil menurunkan gangguan muskuloskeletal dari kategori tinggi, menengah dan rendah menjadi kategori menengah, rendah dan sangat rendah. Penenun tradisional Sarung Samarinda disarankan untuk tetap menjalankan kegiatan ini di sela-sela pekerjaannya sebagai salah satu upaya pencegahan gangguan musculoskeletal.

\section{Acknowledgements}

Ucapan terima kasih disampaikan kepada Fakultas Kesehatan Masyarakat Universitas Mulawarman yang telah memfasilitasi kegiatan ini, seluruh penenun Tradisional Sarung Samarinda dan mahasiswa Fakultas Kesehatan Masyarakat Universitas Mulawarman yang telah berpartisipasi dalam kegiatan ini.

\section{Daftar Pustaka}

Anderson, B. (2010). Stretching in The Office (Peregangan untuk Orang Kantoran). (M. S. Nugraha, Ed.). Jakarta, Indonesia: Serambi Ilmu Semesta. 
Bhattacharya, A. (2014). Costs of occupational musculoskeletal disorders (MSDs) in the United States. International Journal of Industrial Ergonomics, 44(3), 448-454. https://doi.org/10.1016/j.ergon.2014.01.008

Bureau of Labor and Statistics, U. D. of L. (2016). Nonfatal Occupational Injuries and Illnesses Requiring Days Away From Work, 2015. Retrieved from http://www.bls.gov/news.release/osh2.nr0.htm

Dinar, A., Susilowati, I. H., Azwar, A., Indriyani, K., \& Wirawan, M. (2018). Analysis of Ergonomic Risk Factors in Relation to Musculoskeletal Disorder Symptoms in Office Workers. KnE Life Sciences, 4(5), 16. https://doi.org/10.18502/kls.v4i5.2536

Harwanti, S., Ulfah, N., \& Aji, B. (2017). Pengaruh Workplace Stretching Exercise Terhadap Penurunan Keluhan Musculoskeletal Disorders(MSDs) Pada Pekerja Batik Tulis Di Kecamatan Sokaraja. Kesmas Indonesia, 9(02), 49. https:/ / doi.org/10.20884/1.ki.2017.9.02.158

Hogan, D. A. M., Greiner, B. A., \& O'Sullivan, L. (2014). The effect of manual handling training on achieving training transfer, employee's behaviour change and subsequent reduction of work-related musculoskeletal disorders: A systematic review. Ergonomics. Taylor \& Francis. https://doi.org/10.1080/00140139.2013.862307

Kementrian Kesehatan Republik Indonesia. (2019). Evaluasi Kinerja Pembangunan Kesehatan.

Leyshon, R., Chalova, K., Gerson, L., Savtchenko, A., Zakrzewski, R., Howie, A., \& Shaw, L. (2010). Ergonomic interventions for office workers with musculoskeletal disorders: A systematic review. Work, 35(3), 335-348. https://doi.org/10.3233/WOR-2010-0994

Loghmani, A., Golshiri, P., Zamani, A., Kheirmand, M., \& Jafari, N. (2013). Musculoskeletal symptoms and job satisfaction among office-workers: a crosssectional study from Iran. Acta Medica Academica, 42(1), 46-54. https://doi.org/10.5644/ama2006-124.70

Luttmann, A., Jager, Ma., Griefahn, B., Caffier, G., Liebers, F., \& Steinberg, U. (2003). Preventing Musculoskeletal Disorders in the Workplace. World Health Organisation Report Geneva. https:/ / doi.org/http:/ / www.who.int/iris/handle/10665/42651

Muhamad Ramdan, I., Candra, K. P., \& Rahma Fitri, A. (2018). Factors Affecting Musculoskeletal Disorder (MSD) Prevalence among Women Weavers Working With Handlooms in Samarinda, Indonesia. International Journal of Occupational Safety and Ergonomics, 1-23. https:/ / doi.org/10.1080/10803548.2018.1481564

Muhamad Ramdan, I., Duma, K., \& Setyowati, D. L. (2019). Reliability and Validity Test of the Indonesian Version of the Nordic Musculoskeletal Questionnaire (NMQ) to Measure Musculoskeletal Disorders (MSD) in Traditional Women 
Weavers. Global Medical \& Health Communication (GMHC), 7(2), 122-129. https://doi.org/10.29313/gmhc.v7i2.4132

Purwadi. (2015). Kajian Sarung Samarinda Dari Prespektif Pemangku Kepentingan. Kinerja, 12(2), 89-101.

Rovitri, A., Lubis, H. S., \& Sinaga, M. Ma. (2015). The Difference Of Musculoskeletal Disorder Before And After Workplace Stretching-Exercise On Badrul Aini Child And Maternity Hospital Medan In 2015. Jurnal Lingkungan dan Kesehatan Kerja, $4(2), 124-132$.

Scheneider, E., \& Irastorza, X. (2010). Work-related musculoskeletal disorders in the EUFacts and figures. Luxenbourg: European Agency for Safety and HEalth at Work. https://doi.org/10.1007/BF03344315

Sekaaram, V., \& Ani, L. S. (2017). Prevalensi musculoskeletal disorders (MSDs) pada pengemudi angkutan umum di terminal Mengwi , Kabupaten Badung-Bali (The prevalence of musculoskeletal disorders (MSDs) in drivers of public transport in Mengwi terminals, Badung-Bali regency, Indonesia). Intisari Sains Medis, 8(2), 118-124. https://doi.org/10.1556/ism.v8i2.125

Stock, S. R., Nicolakakis, N., Vézina, N., Vézina, M., Gilbert, L., Turcot, A., ... Beaucage, C. (2018). Are work organization interventions effective in preventing or reducing work-related musculoskeletal disorders? A systematic review of the literature. Scandinavian Journal of Work, Environment and Health, 44(2), 113-133. https://doi.org/10.5271/sjweh.3696

Valsangkar, S., \& Sai, K. S. (2012). Impact of musculoskeletal disorders and social determinants on health in construction workers. International Journal of Biological and Medical Research, 2(4), 1727-1730.

Wahyono, Y., \& Saloko, E. (2014). Pengaruh Workplace Exercise Terhadap Keluhan Muskuloskeletal Pada Pkerja Di Bagian Sewing Cv. Cahyo Nugroho Jati Sukoharjo. Jurnal Terpadu Ilmu Kesehatan, 3(2), 197-203. Retrieved from http://jurnal.poltekkes-solo.ac.id/index.php/Int/article/view/104/94 


\section{JURNAL ABDIMAS BSI}

Jurnal Pengabdian Kepada Masyarakat

Lampiran foto lokasi pengabdian masyarakat, penenun tradisional, pengkajian data MSD dan latihan peregangan otot
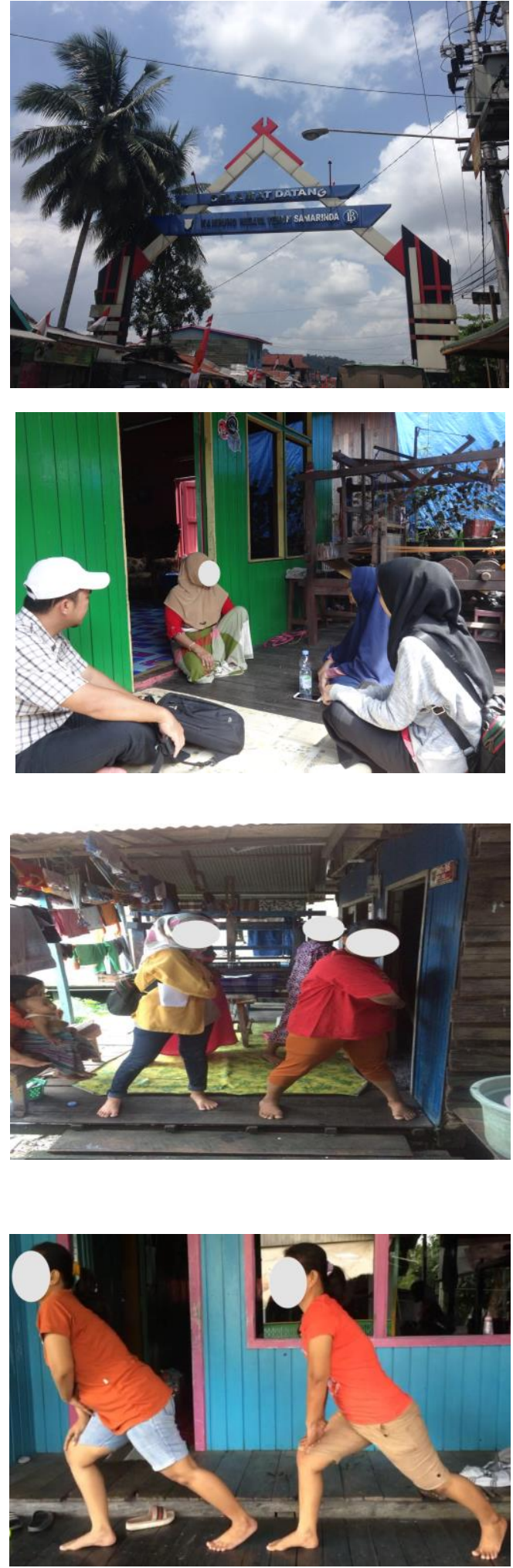
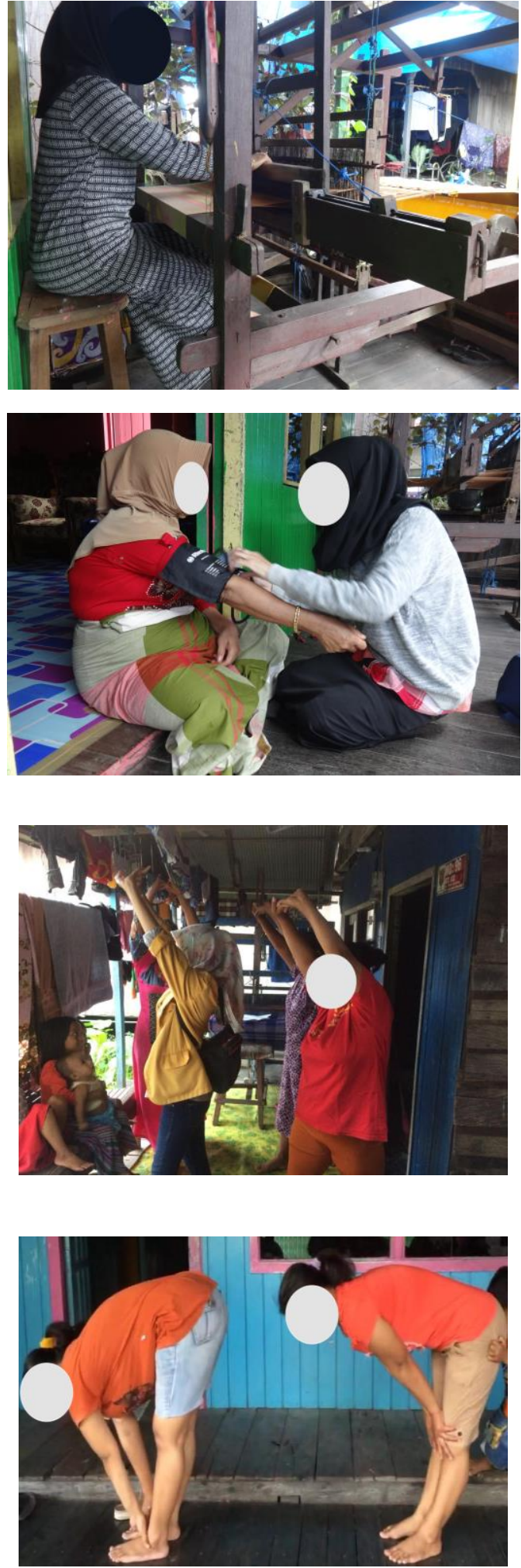